\title{
On Chinese Trainees and Interns in Japan*
}

\author{
Jiaoyan Fan \\ School of Law, Three Gorges University, Yichang, China. \\ Email: fjy1213@hotmail.com \\ Received April 27 ${ }^{\text {th }}$, 2012; revised May 26 ${ }^{\text {th }}, 2012$; accepted June $6^{\text {th }}, 2012$
}

\begin{abstract}
There are millions of Chinese workers in Japan, most as trainees and interns hired in small or medium sized industries. While they work hard and contribute great to the economic development of Japan, there also exist some problems arising from the mechanism which have to be faced by both Japanese and Chinese governments. On analyzing the status of the trainees and interns, the author exposed some problems in the system, and presented some suggestions from the legal view for the future at last.
\end{abstract}

Keywords: Chinese Trainees and Interns in Japan; Problems and Disputes; Labor Law

\section{Introduction}

Rights-oriented issues were called increasingly heavy attention during this time, especially issues concerning migrant workers' rights, which have brought about a lot of discussion in the international community, for example, the protection of the rights of domestic workers has made famous progress, for a convention concerning decent work of domestic workers has been adopted by the International Labor Organization (Hereafter it is abbreviated as ILO). It's a great progress in the protection of migrant workers' right. Nonetheless relatively little attention has been paid to Chinese trainees and interns in Japan except several reports on Internet. Academic researches and studies are urgently needed in this field, and the law concerned their legal protection must be taken into consideration between China and Japan. They deserve such attention for their positive contribution to the economic development in Japan in contrast with their current status. It will discuss the status of Chinese trainees and interns in Japan after some introduction. Then I will reveal the problems in this regime, and put forward some suggestion, hoping that my suggestion may accelerate the cooperation between Japan and China, and providing some practical help to bringing benefits to both Japanese entrepreneurs and Chinese workers.

\section{The Background and Development of Chinese Workers in Japan}

With the development of Chinese economy and technol-

\footnotetext{
${ }^{*}$ This essay is one of the research result of the project of the Ministry of Education in 2009 presided by Jiaoyan Fan. The project title is: Legal issues on protection of overseas Chinese labors' rights-from the perspective of private international law, the research number is: 09YJA 820039.
}

ogy, more and more Chinese people go abroad to make a living, and it's also due to the great population and the current employment problem in China. Among these people a great amount go to Japan, Singapore, Russia, South Korea, the Middle East Asia and Africa. It's said that there are more than 80 million Chinese are working overseas in 2010 by Chinese Commercial Department [1], while in Japan there are more than 50,000 people every year which account more than 60 percent of Chinese overseas workers [2]. Most of them are younger people in age of 20 - 35 years old, and most are female who are not married. They often enter into textile, product and electronic factory. They can only stay three years at most as temporary labor force in the regime of Japanese Trainee and Intern System which built to relieve the pressure of shortage of labor force and avoid the problem of immigration.

Most of the trainees or interns come from rural Chinese areas, where they are or will be migrant people in domestic cities. Their parents are most farmers, and they don't want to go on working in the field for low productivity and efficiency, and also it is one of the most important factors that the land couldn't bear so many people for a living. Most choose to work in a Chinese city, some choose to go overseas to adventure an opportunity. Most of them are in low educational qualification, and are graduated from junior middle school at the age of 16 - 17. It's not easy for them to find a good job or establish good career. They don't want to go on education for economic reasons or the competition for ideal colleges. They also witness many seniors who have gone to college could not find a good job. They leave school earlier and want to make a living as migrant workers in China so that they could help their parents to live better. 
In some district in China, there are towns or villages, even cities, with so big population which have worked in Japan as trainees and interns that they are called Japanese Town, Japanese Village or even Japanese City. For example, Yanghe Town in Yingcheng City in Hubei Province, renowned for its big population of trainees and interns in Japan, is called Japanese Town by the local resident. Most people in the town have been to Japan as trainees and interns. It is relatively poor in Yingcheng City, with dense inhabitants and poor public facilities, the young people seldom receive higher education than junior middle school, some even didn't graduated from primary school. In this town, you will mistake it a Japanese town or village, where people behave as a Japanese, men bow politely when they meet, women dress like Japanese women sometimes, and style of life is quite of Japanese. There are new buildings, here and there, quite of Japanese style. They are made by the returners to remember the lives in Japan. They usually conceive a kind of deep emotion to the place where they have lived for three years and miss their friends in Japan.

Initially there are quite few people going abroad to work. There is an old Chinese saying that a doglike home is better than a golden or silver home if it's belonging to you at your hometown. For people from the middle of China Mainland, they are usually quite conservative and reluctant to move to alien areas in contrast with coastal people such as those from Guangdong, Fujian province. While life was so tough, some adventured to Japan to be as trainees and interns in early 80s of the last century, and returned with great fortune. The returners experienced the better life in Japan, and they helped and arranged their relatives to go abroad, their sisters, their brothers, their cousins etc. Good examples were told and happy lives were witnessed, for there they found a wonderful land to make a living. For nearly 30 years more and more young people keep on going and coming back, and the Japanese Town was formed.

Whereas in other places the situation is quite different, where there are so little people who would like to go abroad to work. For example in Yichang City also in Hubei Province where the Three Gorges Project is seated, the farmers there often grow oranges or vegetables to make a living, and they could make a living on the land. Most young people would like to depend on the land, or work in Yichang City near the town or village. It's said there are only 23 people working abroad in 2009 in Yichang City while the number is over a thousand in Yingcheng City, with the population only one third of the former.

The reasons may be complicated, for example, the geographic advantage of the Three Gorges Project, for which the young people is easier to find jobs, and the economic situation is better than Yingcheng City histori- cally, and there are also other elements such as life styles and customs et al. Nonetheless the most important element is idea. When I investigated some people, they said: it's so terrible to work overseas, the boss will not pay and they will not let you come home if you irritate them. Some told: I don't want to work in so unknown a place, I feel not safe mentally. Others insisted that there will be quite tough work abroad while they can not earn much as what they work. They said they would like to earn less but the life is steady and can be controlled.

It's world renowned that China has a so great population in the world and the earning is relatively low in the world. A great amount of people cannot live on the land in their home town, and they have to go out to make a living in bigger cities such as Wuhan, Shenzhen, Guangzhou, Shanghai, or even Beijing. They can earn a good living by their hands and sweet though the pay is usually not high. When there are good examples to work in Japan, they also would like to go abroad. They would like to go adventure for a better life.

\section{Status of Chinese Trainee and Interns in Japan}

The trainee and intern mechanism in Japan was set up in Japan in 1990s aiming to provide opportunities for foreign trainees to learn advanced skills in Japan. It's true for the initiative, but it's criticized for taking advantage to supplement the shortage of labor in Japan. There are numerous descriptions on the misery conditions of migrant workers in literature, and it is true to mirror the reality of the migrant workers, but in some places, the story was told with different happy ending. In Japan the trainees can receive a monthly allowance of 60,000 yen or more generally, but the maximum of 9.5 million yen [3]. For Chinese trainees from underdeveloped rural area, such treatment is generous and attractive. Optimistically the mechanism is good both for Chinese workers and Japanese medium and small factories.

\subsection{Good Examples}

Example 1. Xiao Ying, a young girl, fine and a little pale, is aged only 20. She had come back from Japan for about one year. I met her in her parents' house which is quite dim and narrow. When I asked her what impressed her most in Japan, she told me that she had very happy time in Japan and she missed Japan very much, and she wished she could have opportunity to go back there one day. She said in thoughtful expression and a bit sadness. "But it's impossible," she said, "I can never come back to Japan again, for I have finished my study there.” Then she told me her three years' life in Japan. She told me that she worked in a small clothing factory where there are only 15 workers, in which most of them are Japanese 
old women while only 3 Chinese including her. Every day they worked 8 hours, 8 - 12 in the morning and 1 - 5 in the afternoon, and there was only one hour for lunch and a quarter break between 10 to 12 in the morning. They would work overtime when there is much work to do. They work hard every day, and don't feel unhappy. They cooked for themselves after work, and the lodging is well equipped and the living conditions is better than in China .The boss was kind paying on time and caring them much. He bought them typical Japanese snacks once or twice a week and took them on vocation 2 or 3 days a month, so they felt relaxed and fresh when they came back. She also met friends in Japan, and they are kind to them. It's so happy and valuable time that she will treasure it all her life. In the three years she earned a great amount for her family, and they will buy a new house in the city with the money so that they could live better. For herself, she could work in spare time and have more time to plan for her future.

I was happy and moved by her story. I believe it is happy and impressive experience for her to work in Japan. When I inquired more about lives of other Chinese workers in Japan, she told me that she was lucky to have a good boss, while for those who were not so lucky, they lived something miserable. Some bosses were mean and harsh, and she also heard a women suicide for missing her child and her husband or some other reasons. But she told me that a great majority of Chinese people are as lucky as her, and they had happy lives in Japan. For her, Japan is a well-developed and civilized country, where people lived there quietly and happily, open and friendly. She liked Japan, and she wished she could go back one day, to see her boss and her friends and all in Japan.

When talking about what's her problem at present, she told me that she could not get a satisfied job in China. In China, the job she could get is so low-paid and boring, something because she is only graduated from a Chinese junior middle school. She is good at clothing, but she didn't want to work in a clothing factory any more, because she had worked as a clothing worker in Japan, with 3 years' hard working, and she wanted to experience other job. I suggested her to go on studying in some technical school or to go to college, but that's too hard for her, a junior middle school graduate.

I heard that Xiao Ying has found a job in Singapore or Malaysia later. I blessed her a better future.

Example 2. Chen is a married women, 30 years old, tall and beautiful. Now she worked in her own car maintenance factory with her boyfriend. She also worked as a trainee and intern in a Japanese clothing factory for 3 years, from 2006-2008. She has a 7 years old son and divorced in 2009 after coming back from Japan. She said her ex-husband is so idle and so dependent on her eco nomically. Her experience in Japan is not quite happy. The boss was harsh to them, and she didn't have enough work to do, and there was no overtime work, so she earned much less than Chinese workers in other factories. The boss was not in a due business so that he often delayed to pay. They had conflicts with the boss when he could not pay or he had no work for them to do, when the conflict occurred, the workers were always in a disadvantage position, some workers were detained by force in black house for several days, and they were freed only when a representative from Chinese recruiting institute came to consult and guarantee for no resistance any more. But all their wages were paid finally before they came back to China, except some insurance fees which should return. She told me that Japanese government supervised so that the workers can be paid. She told me that though she was not very happy in Japan, it's worthy to go working there, for the country is so developed and prosperous, and the people there are friendly and working hard, she learnt more and knew more there. She divorced because her husband is so lazy and idle, he didn't want to make his career by himself, she didn't earn much in Japan, so she had to work hard. She opened a car maintenance factory with her boyfriend after divorce. Now all she wanted is to earn more money and to live her own life independently.

Xiao Ying and Chen have different experience in Japan, but they both treasured their experience in Japan. They loved Japan and cherished the friendliness between Chinese and Japanese people and they are impressed by the Japanese culture and his development. May it be a long time for them to return, mentally or in life styles.

\subsection{Bad Practices}

However, there is a gap between ideals and reality, Japan is not paradise. There are also bad examples. One of the notorious incident occurred in December 2005, which is called "the Incidents of Huang Shi Women Workers".

Six female workers from Hubei province were sent by the Huangshi-based Dongchuang Overseas Labor Service $\mathrm{Co}$, which is one of the 21 legitimate overseas labor service agencies based in Hubei, to train as clothing workers in Japan. One year later, they became interns. But the women were actually working for Techoclean, a clothes washing firm. The women often had to work late in the night including Saturdays and Sundays. For their overtime work, they received compensation of 300 to 400 yen when the minimum overtime wage was supposed to be 810 yen. When they learned from a Japanese publication that this pay level was illegal in Japan, they talked with the company director and demanded improvement of working conditions and back pay. The director promised a response 3 days later. On the morning of the third day, August 22, a dozen men and women broke into their 
dormitory and dragged them onto a vehicle. One worker named Hu escaped but the other five were tossed into the vehicle. On the way, the workers tried to jump out of the vehicle, and they were beaten again. When the vehicle arrived at the airport, the airplane had already left. So the workers were taken back to the dormitory. Duan was able to escape by climbing out of a window eventually and contacted with the other escapee $\mathrm{Hu}$. They were found and taken to the Japanese labor union headquarters later. A third woman named Zhang also broke her leg while trying to jump from the second floor to escape. On August 25, the director of Technoclean admitted by pressure: "If these were Japanese citizens, the company would not have sent them back by force. We feel very sorry to cause the injuries to the female workers." He admitted the violation of Japanese wage law, and he would compensate back, but he denied what he said later [4].

Another bad example is on young a man, Kou Binfeng, who worked in a food factory for 2 years, and fell ill for heavy physical labor, but the company refused to cure him and wanted to get rid of him for a sum of money which is far below the cost needed for curing [5]. He left Japan sadly without fair compensation.

Of these bad practices, there arise lawsuits constantly , for example, a group of 14 Chinese trainees and interns on November 30 filed a lawsuit with the Tokushima District Court against a sewing company where they worked, demanding 140 million yen in back pay [6]. They also claimed damages against the company for infringing on human rights and forced labor. There is also report on which the family of a Chinese trainee Jiang Xiaodong filed a 57.5 million yen damages suit with the Mito District Court in 2011, arguing that Jiang's death was caused by overwork at a metal processing firm in Itako, Ibaraki Prefecture [7].

\section{Law Concerns}

\subsection{Current Legal System}

Since these years Japan has developed a comparatively complete set of legal norms. The most important legislation is Immigration Control and Refugee Recognition Act, which was amended in July 2009 and took effect in July 2010. It regulates the basic activities of recruiting foreign technical intern trainees. On December 2009 the Japanese Ministry of Justice and Immigration Bureau published Guidelines concerning Entry and Residence Management of Technical Intern Trainees, which sets up more concrete rules for all the parties in the program, such as the sending organizations, the receiving companies, the supervising organizations and intern trainees. These laws and regulations consist of the basic current legal system. Other laws such as Japanese contract law, labor contract law, labor standard law and other related laws should also be observed in the process of recruiting foreign intern trainees, especially when there are abuses or incidents happened. The laws and regulations guarantee the basic rights of foreign workers [8]. Nonetheless it must be mentioned that before 2007, the trainees were not treated as migrant workers and there existed no labor contract between the trainees and the company during the one year training period. The minimum standards to protect workers cannot apply, and the status of the trainees is quite vulnerable. After the implementation of the new regulations, the situation is improved, and the trainees are treated as workers while the training period is shorten to 6 months.

The Japan International Training Cooperation Organization (Hereafter it is abbreviated as JITCO) is a Japanese government sponsored institute to administrate the whole activity of recruiting the trainees and interns, which consists of officials from five main government ministries, including the Ministry of Justice; the Ministry of Health, Labor and Welfare (Hereafter it is abbreviated as MHLF); and the Ministry of Economics, Trade and Industry. It's effective to deal with issues arising from the program, for multi-government department can be cooperated well to deal with disputes. The program has been designed to be helpful both for Japan and the sending countries.

JITCO had issued its goals and guidelines in its "Operative Manual for Sending Organizations". The manual states that the purpose of Japan's foreign trainee and internship program is to foster the development of human resources in ways that would contribute to the industrial development of other nations. After 2007, the mechanism was reformed and JITCO published Technical Intern Training Guidebook for Technical Intern Trainees, Guidelines on Allowance for lectures, wages, and management arrangement expenses in Technical Intern Trainees Program (Hereafter it is abbreviated as TITP) and other documents. While the Technical Intern Training Guidebook says TITP is a program where young workers from various overseas countries acquire industrial and vocational skills as technical intern trainees at companies in Japan, and then improve their acquired skills through further two years technical intern training, so that they can utilize such skills for economic and industrial development after their return to home countries. In other words, the TITP aims to develop human resources who can contribute to the industrial development of foreign countries through transfer of Japanese technology. Nonetheless they are on the same direction.

These are all regulative documents to adjust the relationship between the parties [9]. According to the regulations, the training institutes which receive trainees should be equipped with life instructors and mentors, provide 
free accommodation, be responsible for participating specified insurance policy for the trainees and some other proper living conditions. The sending organizations and intern trainees also must obey the regulations strictly. They are better for the protection of technical intern trainees' rights.

In addition to the aforementioned laws and regulations, Japanese constitutional law entitles foreigners in Japan the equal basic rights as Japanese, it should be obeyed when there are disputes between the parties, and the laws and regulations concerned should comply with the constitutional law. In fact it is the supreme law in the field.

In China, the workers are usually dispatched by sending companies which have been authorized by China Commercial Department. They are considered as intermediary companies in charge of recruiting workers in China. But the character of the contracts between the interns and intermediary companies is not clear, they are usually not regarded as labor contracts, and in practice the workers cannot receive protection from Chinese labor law. Different opinions on it are discussing, and more concrete laws are needed in practice.

\subsection{Existing Problems}

Though Japanese labor law is said to be very powerful, it is of limited use in protecting trainees. There are a lot of problems. For example, for no payment to overtime work, it's difficult to find proof, or even there is no proof of (overtime) work. Which more often happened is that the trainees do not have the resources and they don't know how to seek help and advice from labor unions and local labor standards offices for language or cultural obstacles. Inaccessibility to assistance is further exacerbated by the fact that companies that recruit trainees and technical interns are often located in suburban and rural areas throughout Japan.

On protection of human rights of employees, the legal mechanism should be effective. It's reported employers dismiss technical interns in mid-contract, by using threats, lies, and force, when they faced legal risk for the intern trainees who try to seek help or compensation, for their maltreatment. Some employers have hired security companies to escort the technical interns to the airport and repatriated them to their home countries. It's the result of the vulnerable status of Chinese workers in Japan, and there are serious legal loopholes existed in the system. It's said the forced repatriation process is often carried out very expediently, leaving the technical interns with little time and limited means to run away or seek help.

In China, there is also no specified law to regulate foreign-related labor relations. While labor law applies only to work performed in China, some regulations are made by Chinese Commercial Department or other depart- ments which don't have uniform effect. Also the remedy mechanism is not perfect in China. If a Chinese worker is damaged in Japan for the employers' violation of labor law, they don't know where to claim. There is no clear law for them to sue foreign employers in China, so the court may not accept but pass it to arbitration; if they file a sue in foreign country, it's too difficult especially after they are sent back to China.

There also concern international laws on migrant workers right, such as ILO conventions and UN treaties on migrant workers rights. Since ILO conventions are very important to protect immigrant workers [10], both China and Japan should try to adopt them. Theoretically, these trainees and interns are not international migrant workers, for it's said in Japan that they are technically "students". Neither the companies which arrange to send trainees overseas nor the Japanese companies which accept them, are subject to related laws strictly. Further clarification is needed on whether the international treaties should apply for the treaties are usually quite princeple and abstract, and their implementation is quite crucial so that the trainees and interns can entitle the corresponding protection.

Another important instrument is bilateral treaties between the sending and receiving countries to deal with issues arising from the program. It's helpful and convenient, for protecting the benefits of both parties. There are such treaties between China and Japan, but it's not for the intern training program typically.

Other legal instruments are also at stake, such as conflict of labor laws, which concerns which law to apply when dealing with disputes between Japanese and Chinese parties, and work place torts as well [11], where further research should be conducted in the field.

\section{How to Improve the Mechanism in the Future}

It can be seen from the medium that constant critics arise in Japanese foreign trainees and interns mechanisms. It is said that the mechanism has become an exploited source of cheap labor in a country with one of the world's most rapidly aging populations, lowest birthrates and closed immigration policy. It's true from the reality, and the mechanism can go on only if Japan could make profit from it. But it should also pay more attention to the protection of foreign workers. Since it should be benefit to both sides of the sending and receiving countries, the best way to achieve the goal is to solve the problems on mutual understanding and cooperation.

It is obvious there exist some serious problems in the mechanism, neverthelessly the author presents some suggestions from the legal review to improve the mechanism in the future. 


\subsection{First, and Most Crucial Is to Protect Overseas Chinese Workers in Japan by Legal Measures}

It's reported in Japanese MHLW that 1209 companies violate the Labor Standards Law, account $74 \%$ of the supervised companies, and reach the peak of recent years, including forced overtime work without the normal procedures (573 cases); no payment or full payment for overtime for overtime work (499 cases); overdue payment (355 cases); mal dormitory and security (155 cases); violation minimum wage laws (159 cases) and etc.

Other kinds of abuses are also reported in media, such as taking away the passports or health insurance cards of the trainees. The trainees were also forced to place their wages in factory savings accounts in order to prevent them from leaving the factory. The factories did not pay overtime, and they skimmed the workers' room and board, and heating and lighting, expenses. The trainees were also forced to pay fines like $¥ 15$ per minute to go to the bathroom during their work hours, or $¥ 2000$ for forgetting to clean their facilities after their shift. There were also accusations of sexual harassment by management. In Japanese government records it's reported that at least 127 of the trainees have died since 2005, or one of about every 2600 trainees [12], which experts say is a high death rate for young people who must pass stringent physicals.

It's the most urgent aspect to protect workers. If it is a dangerous area for people to come, and if the bad practices prevail, the people will be stunned to stay at their home countries and the personal source will be shrunk. It is not the win-win model for both countries.

In accordance with International instruments and national laws of both China and Japan, Chinese workers in Japan are entitled to equal treatment in labor rights as the Japanese workers [13]. Japanese labor-related laws and regulations which protect workers shall be applied to technical intern trainees from the time they start activities to acquire skills at accepting companies. In Technical Intern Training Guidebook for Technical Intern Trainees by JITCO accepting companies must give technical intern trainees at least one day off per week or four days off in a four-week period, annual paid leave is to provide in order to recover from physical and mental exhaustion, social security and labor insurance should be arranged for the workers, the technical intern trainees should be provided consultation services and support in order to ensure their legal rights provided by Japanese laws and regulations and so on [14]. Should the laws to be observed strictly, Chinese trainees and interns can be protected better than current time.

Attention must also be paid to training mechanism in China. Before the workers are sent abroad, they usually are trained for working and living in Japan for 1 or 2 months, some are trained even longer than 6 months. They are lectured Japanese and Japanese culture and model of conduct. They behave quite like Japanese even before they go to Japan. Of course it is important, but they should also be educated to protect themselves when they are treated unfair and know how to protect themselves legally, for there are so unscrupulous employers everywhere, and tolerance may incur more and severer abuse. The training mechanism should be guided by the labor administration.

\subsection{The Second, More Social and Humane Elements Should Be Taken into Account in Legislation and in Practice}

Nowadays the Japanese trainees and interns mechanism is manipulated mainly by business, the profit is the most important considerations of the Intermediary companies in China and the companies in Japan, and thus there are quite high charges for the trainees before they come to Japan. Though regulations in China stipulates that intermediate corporations for overseas labor cannot charge more than 12.5 percent of the total salary of the employment contract for their services. In practice, the regulation is often ignored. It's usually 35,000 RMB for each person going as trainees and interns in Japan, and it's not a small amount for young people or their rural family. For this they have to work overtime as much as possible. Work more save more is the basic dogma of the workers, and a lot of problems arise from it. For employers, they know what the workers want, and it's easy for them to abuse the worker in all kinds of form, for workers, they have to stand all kinds of unfair treatment for they have to work for the fee they have cost and earn a living for themselves and the family. The high charge also restraint the sources of people who want to go to work overseas. It's difficult usually for young people to have this amount of money, even by borrowing from their relatives and friends. In some cities in China, the government will sponsor the quasi-trainees, but only a small amount. It can be a good example, and will help a lot if the amount rises to most of the money or half of the fees. For Japanese social organizations or government institutes, it's also a kindness to help the trainees. Of course it will be better if the fee can be lowered to an acceptable level or canceled, but it can not be resolved the moment because the current recruiting model has been established for years.

The work is usually physically demanding for trainees and interns, and the workers' health and security should be guaranteed. Except for social security, it's the same important for the workers to be given labor law protection. The workers should be granted rights from Japanese 
Labor Standard Law, and thus they should enjoy holidays, and labor protection. Before 2007, trainees are not treated as employees, and no labor rights are entitled therefore. After that time, all trainees and interns are treated as employees, and they should enjoy equal treatment as workers in Japan. They should be entitled to take part in all kinds of activities permitted by Japanese Law, including social organization, collective bargaining as members of union, et al. Just as aforementioned most Chinese trainees and interns are low educated, lectures and other essential help should be given to them on how to protect themselves via Japanese Social organizations or government institutes. A few Chinese legal service agency or social organization should be set up in Japan to help Chinese workers. And the cooperative institutes between Japan and China are also appreciated. All these should be promulgated in law and guarantee the implementation by governments and social organizations.

\subsection{Further Cooperation Is Urgently Needed between Two Governments on Bases of International Law}

On the current status, more cooperation is needed. Many hands make light. While a bilateral treaty between Japan and China has been set up a base for all forms of cooperation [15], a more specific bilateral agreement is needed to solve legal problems in the mechanism. Both for Japanese government, who need to absorb manpower from China to prosper its domestic small and medium-sized industries, and Chinese government, who is in need to enrich his people and relieving unemployment problem, should put Japan-Sino labor cooperation issues on a strategic height, and set up a longtime consultation and coordination mechanism of the issue, to protect the basic human rights of the trainees and interns in Japan. On this issue, any one part can not solve the current problems completely, whatever one endeavors to. And also it must be intervened by governments of both countries, not only by entrepreneurs, government departments or social organizations. There are so many Chinese workers in Japan, and so many companies concerned with Chinese workers, they deserve both governments to pay sufficient attention to reach some cooperation agreement.

\section{Conclusion-Looking for a Good Future}

The Japanese industrial training and technical internship program opened a door for hard working Chinese workers to make livings, and it also incurred numerous controversies all over the world. Critics mainly focus on that contradiction between its claimed target and its real purpose. It was claimed that this system was designed to support foreigners in their acquisition of technical skills and knowledge of Japanese advanced technology, but it is really a source of cheap labor to make up for the shortage of unskilled labor in Japan. Therefore there are legal loopholes, and correspondent problems brought about both in Japan and China. Incidents occurred frequently for the violation of worker and human rights of trainees and interns.

Nonetheless the mechanism had existed for years, and it contributed much to both countries. In reality most Chinese trainees and interns benefit from this mechanism and it helps to promote the friendly communication between the two peoples [16], though reforms are urgently needed, and further cooperation should be advocated.

Chinese are the most honest, hard working and tolerant people in the world. Good examples lead them to Japan and they treasured the experience. They go abroad with dream, and the realization of the dream is so beautiful. They love it and they will keep it in heart for a long time. They may go on to their son, on and on, the beautiful experience of the working in Japan. The friendship between the two peoples will keep from generation to generation.

May TITP have a good future.

\section{REFERENCES}

[1] Chinese Commercial Department, "Brief Statistics on Foreign Labor Service Cooperation and Business,” 2011. http://www.mofcom.gov.cn/aarticle/tongjiziliao/dgzz/201 109/20110907749790.html

[2] J. Hays, "Foreign Workers in Japan and Problems with Japan’s Foreign Trainee Program in 2008,” 2011. http://factsanddetails.com/japan.php?itemid=1769\&catid $=18$

[3] J. L. Hou, "It's Japanese Duty to Protect Overseas Chinese Trainees and Interns,” New Overseas Chinese Newspaper, 1 July 2011.

http://www.chinanews.com/hr/2011/07-01/3150720.shtml

[4] Z. Peng, "The Continuing Incident of Hubei Female Workers: Their Life after Coming Back to China," Changjiang Newspaper, 11 September 2008.

[5] B. F. Kou, "Go Working with a Good Dream to Japan While Coming Back Suffering Mentally and Physically: A True Story of a Yingcheng Chinese Trainee in Japan,” 2011.

http://bbs.yc161.com/dispbbs.asp?boardid=46\&id=11592 \&page $=5 \&$ star $=1$

[6] Akahata, "Chinese Trainees and Interns Seek Payment of Unpaid Wages in Court,” Japan Press Weekly, 1 December, 2010.

http://www.japan-press.co.jp/modules/news/index.php?id $=1137$

[7] “Chinese Intern Files Damages Suit,” 2011. http://www.houseofjapan.com/local/chinese-intern-files-d amages-suit

[8] K. Kagawa, "Japanese Labor Laws: Case Studies and Comments,” Deep and Deep Publications Pvt. Ltd, New 
Deli, 2007.

[9] Commercial Office of the China’s Embassy in Japan, “Japan’s Trainee and Intern Program,” 28 February 2008. http://jp.mofcom.gov.cn/aarticle/ztdy/200802/200802054 02683.html

[10] P. Wickramasekera, "Asian Labour Migration: Issues and Challenges in an Era of Globalization,” International Migration Papers, International Labor Office, Geneva, 2004. http://www.ilo.int/public/english/protection/migrant/dow nload/imp/imp57e.pdf

[11] I. Susanti, "The Conflict Rules on the Protection of the Rights of Migrant Workers: A Proposition for Indonesia and ASEAN,” Ulrik Huber for Private International Law Groningen, 2008.

[12] K. Satoshi, “Japan’s Internship Training Program for Foreign Workers: Education or Exploitation?” The Asia-Pacific Journal: Japan Focus, 15 July 2008.
http://japanfocus.org/-Kamata-Satoshi/2820

[13] R. Cholewinski, “The Legal Status of Migrants Admitted for Employment: A Comparative Study of Law and Practice in Selected European States," Council of Europe, The Strasbourg, 2004.

[14] Japan International Training Cooperation Organization, “Technical Intern Training Guidebook for Technical Intern Trainees,” 2012.

http://www.jitco.or.jp/english/overview/english_manuals. html

[15] Ministry of Foreign Affairs of China, "Japan-Sino Science and Technical Cooperating Agreement,” 1980. http://www.fmprc.gov.cn/chn/gxh/zlb/tyfg/t5802.htm

[16] C. K. S. K. Kumiai, "Trainees and Interns Performing at the Chinese New Year Festival,” 2009. http://www.jitco.or.jp/english/information_trainees_intern s/index7-9.html 